See discussions, stats, and author profiles for this publication at: https://www.researchgate.net/publication/334574415

\title{
Compressive strength assessment of recycled aggregate concrete using Schmidt rebound hammer and core testing
}

Article in Construction and Building Materials · July 2019

DOI: 10.1016/j.conbuildmat.2019.07.110

\section{CITATIONS}

13

3 authors, including:

Mostafa Kazemi

University of Liège

12 PUBLICATIONS 100 CITATIONS

SEE PROFILE
READS

565

Jorge de Brito

University of Lisbon

1,441 PUBLICATIONS 16,190 CITATIONS

SEE PROFILE

Some of the authors of this publication are also working on these related projects:

Project In-situ Assessment of Recycled Aggregate Concrete (Finished Project). View project

Project $\quad$ Flexural behaviour of concrete beams reinforced with FRP bars grouted in sleeves (finished) View project 


\title{
Compressive strength assessment of recycled aggregate concrete using Schmidt rebound hammer and core testing
}

\author{
Mostafa Kazemi ${ }^{a}$, Rahmat Madandoust ${ }^{b}$ Jorge de Brito $^{c}$ * \\ ${ }^{a}$ MSc Graduate Student, Department of Civil Engineering, University of Guilan, Rasht, Iran, \\ kazemi.civil68@gmail.com \\ ${ }^{\mathrm{b}}$ Associate Professor, Department of Civil Engineering, University of Guilan, P.O. Box 3756, Rasht, Iran, \\ rmadandoust@yahoo.com
}

${ }^{\mathrm{c}}$ Full Professor, CERIS, Department of Civil Engineering, Architecture and Georresources. Instituto Superior Técnico, University of Lisbon, Portugal, jb@ civil.ist.utl.pt

Corresponding author *

\begin{abstract}
The main objective of this study was to estimate the compressive strength of recycled aggregate concrete (RAC) by means of Schmidt rebound hammer and core testing. The use of recycled aggregate in concrete has been shown to lead to a decrease in the construction cost and it can reduce the burden on the environment by saving natural aggregates. On the other hand, some nondestructive and semi-destructive techniques, such as Schmidt rebound hammer and core testing, are long-established methods for strength estimation of materials. Thus, the present study intended to obtain the compressive strength of RAC using these methods and then compare it with the results of $150 \mathrm{~mm}$ cube specimens. To achieve this goal, after producing concrete mixes with $70 \%$ replacement of recycled coarse aggregate, 96 cube specimens and 8 concrete slabs were cast to perform Schmidt rebound hammer, core and cube testing. In addition, the combination of the methods was used to obtain correlations between Schmidt rebound hammer and core testing. The results demonstrate that a multi-variable equation using these tests' results can efficiently predict the compressive strength of RAC and conventional concrete and is more promising than single-variable equations based on the Schmidt rebound hammer test results.
\end{abstract}

Keywords: Recycled aggregate, Schmidt rebound hammer, Core testing, Compressive strength of concrete 


\section{Introduction}

The extensive amount of construction and demolition wastes produced has imposed a heavy burden on the environment in recent years, and it is estimated that about $67 \%$ of total construction waste materials in the United States is crushed concrete [1-3]. One of the solutions to prevent this serious environmental concern is to recycle waste construction materials and use them in the building process again. These construction materials have drawn the attention of researchers to recycled aggregate concrete (RAC), having both positive economic and environmental impacts [4-9]. RAC has been known as a viable solution in which natural aggregates is replaced with crushed waste. As a new concrete mix design, it was proposed by Frondistou-Yannas [10] over 40 years ago, and the concept of RAC was subsequently analysed and developed by other researchers. Regarding this, Ajdukiewicz and Kliszczewicz [11] assessed the effect of recycled aggregates on the mechanical properties of high-performance concrete. They showed that the compressive strength slightly increased by replacing natural sand with fine recycled aggregates $(0-2 \mathrm{~mm})$.

Zhang et al. [12] and Zaetang et al. [7] showed that the utilization of recycled aggregate led to a decrease in the compressive strength and flowability of concrete. On the other hand, a study by Zhu et al. [13] demonstrated that the presence of coarse recycled aggregate in concrete led to an increase in slump and that $70 \%$ was the optimum replacement level to achieve suitable compressive and splitting tensile strengths. Tam et al. [14] reported similar results, where $50 \%$ to $70 \%$ substitution levels of natural aggregate with recycled aggregate improved the compressive strength of concrete. 
There has always been a need for determining the strength of concrete specimens by means of standard test methods in the laboratory. However, some conditions including compaction, curing, and bleeding will vary in existing concrete at the building site compared to those in the laboratory. So, semi-destructive and non-destructive testing methods have been proposed to realistically estimate the in-situ strength of concrete [15-17]. Of all non-destructive-testing methods, the Schmidt rebound hammer test was first developed by a Swiss engineer in the late 1940s [18]. The device of this test is cheap, portable and easy to operate and its components include hammer, plunger, outer body, and spring. As indicated in Fig. 1, the plunger is pressed forcefully and steadily against the concrete at right angles to its surface. After moving the spring-loaded mass from its locked position, the scale index, known as the rebound number, can be read, while the hammer is still in the test position. This number is dependent on the energy accumulated in the spring and in the mass used $[18,19]$. The feasibility of the Schmidt rebound hammer test was evaluated by Kolek [20], where it was suggested to use it in two types of application, namely precast works and building sites. Victor [21] showed that the rebound numbers of concrete incorporating coarse limestone aggregate were found to be 7 points lower than those of concrete incorporating coarse gravel aggregate, which led to $7 \mathrm{MPa}$ difference in compressive strength of concrete. According to the results of Greene [22], the rebound numbers of lightweight concrete varied remarkably. In addition, there was a difference between the rebound numbers of two concrete samples incorporating the same aggregate from different sources as reported by Grieb 
[23]. However, the rebound numbers at different locations of a plain concrete member were found to be close to each other as observed recently by $\mathrm{Xu}$ and $\mathrm{Li}$ [24].

Among the semi-destructive tests on concrete, the core testing method can be employed at the building site to obtain drilled core specimens using a rotary cutting tool with diamond bits, and reliably assess the on-site strength of concrete elements. In this test, the measured strength of cylindrical core specimens can be affected by some factors including the direction of drilling, length to diameter (L/D) ratio of core, and the presence of reinforcement in concrete [18]. For most practical in-situ testing, the diameter of core specimen has been proposed between 100-150 $\mathrm{mm}$, and it is recommended by ASTM-C42-77 [25] that the L/D ratio of core is close to 2 to reduce uncertainties of correction factors. According to ASTM-C42-77 [25] and BS 1881 [26], the results of compressive strength for a L/D ratio below 1.75 should be modified using some correction factors, as presented in Table 1. As per a study by Sharma et al. [27] on different L/D ratios of drilled core specimens, by changing the L/D ratio, the results of $50 \mathrm{~mm}$ core specimens were affected more than those of $75 \mathrm{~mm}$ core specimens. Meanwhile, the measured strength of concrete increased with decreasing L/D ratio. Similar results were reported by Madandoust and Alizadeh [28], where the effects of diameter, concrete strength level, drilling direction, and L/D ratio on the compressive strength of concrete were detected. They also concluded that the correction factors of L/D ratios for low strength drilled core specimens were found to be close to those of BS1881, while for high strength drilled core specimens these factors were close to those 
of ASTM C 42. Gaynor [29] demonstrated that the presence of reinforcement in concrete led to a decrease in compressive strength of drilled cores between 4 and $18 \mathrm{MPa}$. In addition, Loo et al. [30] showed that the effect of reinforcement on core testing results decreased by decreasing the L/D ratio of drilled core specimens. Furthermore, they showed that the effect of reinforcement ratio up to $4 \%$ on the strength of drilled core specimens with L/D ratio of 1 was negligible.

Some studies have been performed to assess the effects of recycled aggregate on the properties of concrete in laboratory. In addition, a limited number of studies have been conducted to predict in-situ strength of RAC by means of reliable non-destructive and semidestructive testing methods. Concerning this, the effect of crushed bricks aggregates on mechanical properties of concrete was evaluated by Debieb and Kenai [31], where there was a good correlation among the compressive strength estimated by the ultrasonic pulse velocity test, Schmidt rebound hammer and the compression destructive test. Al-Mufti and Fried [32] measured the early age strength and the surface hardness of RAC using non-destructive testing methods. The results showed the similar behavior with age between RAC and normal concrete by means of ultrasonic pulse velocity test and Schmidt rebound hammer. Mukharjee and Bari [33] assessed the effects of Nano-Silica on the properties of RAC using the ultrasonic pulse velocity test and Schmidt rebound hammer. They showed that the properties of RAC were similar to those observed in natural aggregate concrete incorporating 3\% of Nano-Silica. For further investigation, the present study is an effort to realistically estimate the in-situ strength of 
concrete made with $70 \%$ coarse recycled aggregate using Schmidt rebound hammer and core testing. To achieve this goal, cores were extracted from slab samples to prepare cylindrical specimens, where different diameters and L/D ratios of core specimens were tested at 11 and 28 days. In addition, cubic specimens were cast and prepared and tested with the Schmidt rebound hammer at 11,28, 42 and 90 days. Since the curing regimes can affect the mechanical properties of concrete materials [34-37], plain concrete slabs and cubic specimens were cured under both wet and dry conditions. The results of Schmidt rebound hammer and core testing were compared with those of standard cube tests. In addition, a two-variable equation was proposed between Schmidt rebound hammer and core testing to realistically estimate the compressive strength of conventional concrete and RAC under both wet and dry curing conditions.

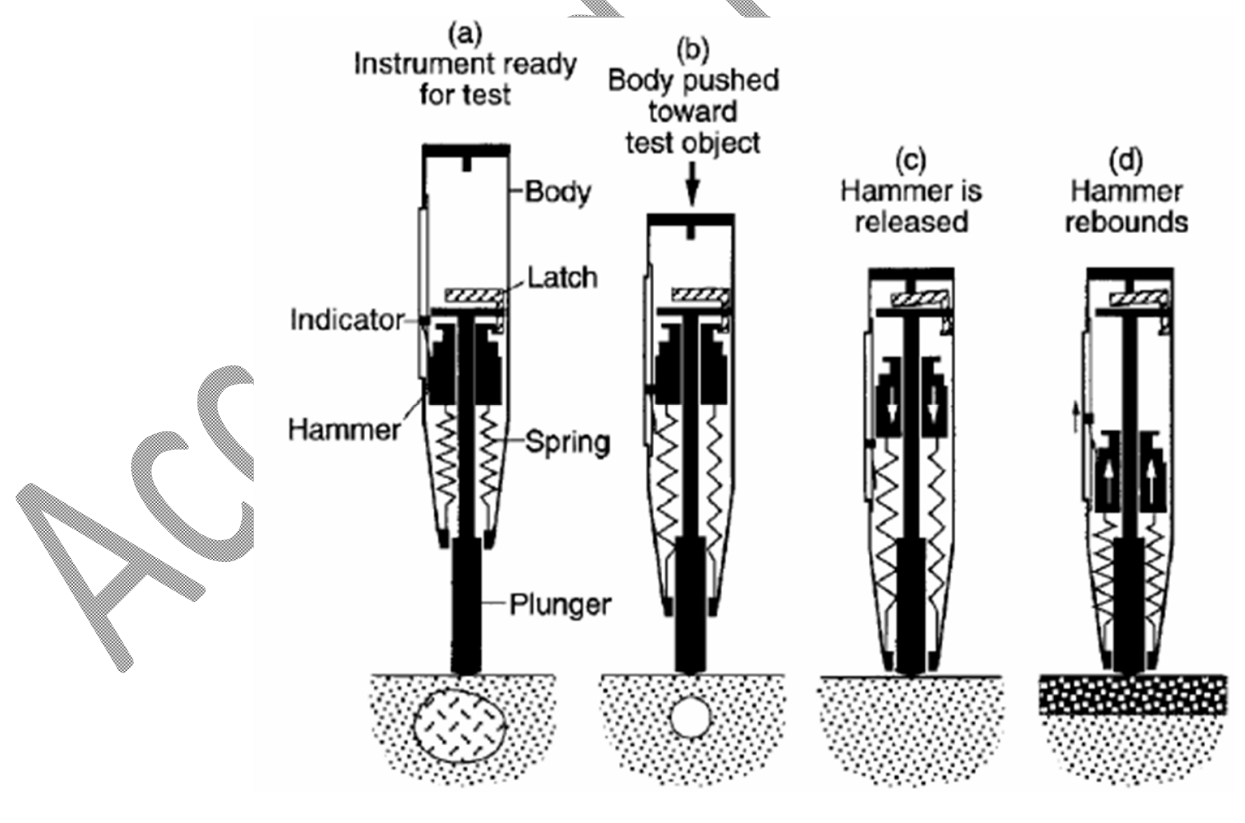

Fig. 1. Schematic illustration of the operation of the Schmidt rebound hammer [19] 
Table 1. Correction factors to modify the compressive strength of drilled core specimens

\begin{tabular}{ccc}
\hline \multirow{2}{*}{ L/D } & \multicolumn{2}{c}{ Correction factors } \\
\cline { 2 - 3 } & ASTM C42-77 & BS1881 \\
\hline 1.75 & 0.98 & 0.97 \\
1.5 & 0.96 & 0.92 \\
1.25 & 0.93 & 0.87 \\
1 & 0.87 & 0.8 \\
\hline
\end{tabular}

\section{Experimental program}

\subsection{Materials}

The chemical composition of Type II Portland cement, with a density of $3.2 \mathrm{~g} / \mathrm{cm}^{3}$ and surface area of $2900 \mathrm{~cm}^{2} / \mathrm{g}$, is shown in Table 2. Crushed gravel was used as coarse aggregate, with a density of $2.65 \mathrm{~g} / \mathrm{cm}^{3}$ and water absorption of $1.1 \%$. Natural river sand, with a density of $2.72 \mathrm{~g} / \mathrm{cm}^{3}$ and water absorption of $5.1 \%$, was used. The size grading curves are indicated in Fig. 2, where the coarse recycled aggregate, with a nominal size of 5-20 $\mathrm{mm}$, was obtained from crushed concrete to produce RAC. A superplasticizer of polycarboxylic ether-type from the Feroplast Company wasused in order to obtain the intended concrete workability [38-41].

Table 2. Chemical composition of the Portland cement

\begin{tabular}{cc}
\hline XRF & Cement (\%) \\
\hline $\mathrm{SiO}_{2}$ & 21.54 \\
$\mathrm{Al}_{2} \mathrm{O}_{3}$ & 4.85 \\
$\mathrm{Fe}_{2} \mathrm{O}_{3}$ & 1.55 \\
$\mathrm{CaO}$ & 64.86 \\
$\mathrm{MgO}$ & 1.55 \\
$\mathrm{SO}_{3}$ & 2.43 \\
$\mathrm{LOI}$ & 1.15
\end{tabular}




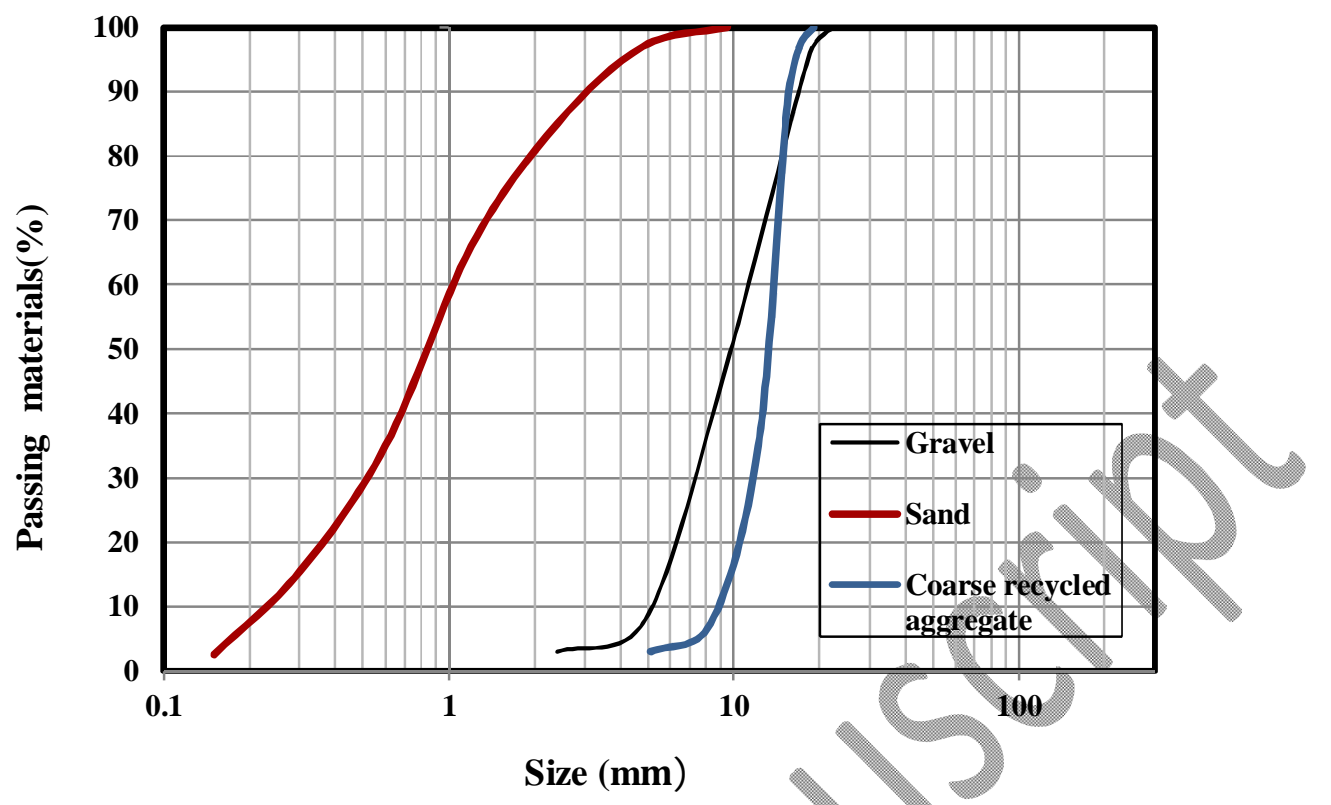

Fig. 2. Aggregates' size distribution.

\subsection{Mix proportioning}

In this study, two concrete mix designs were considered as in Table 3. Mix A is the control mix made with coarse natural aggregate, and Mix B is defined as RAC, where the coarse natural aggregate was replaced at $70 \%$ with coarse recycled aggregate to achieve an optimum mix design as proposed by Zhu et al. [13] and Tam et al. [14]. The effective water-binder ratio was 0.4 for all mixes. All aggregates were used in the saturated surface-dry condition to prevent further water absorption.

For mix preparation, first, the sand, coarse natural and recycled aggregates were mixed for 30 $\mathrm{s}$ at normal speed. Then, half of the tap water was added into the mixer and mixing went on for 1 min. Thereafter, cement was added and mixed for one more minute. Then, the remaining water 
and superplasticizer were introduced in the mixer, and mixing went on for $3 \mathrm{~min}$. Finally, $15 \mathrm{~cm}$ cubes and $100 \times 100 \times 30 \mathrm{~cm}$ concrete slabs were cast to estimate the compressive strength of concrete using Schmidt rebound hammer, core, and cube testing.

Table 3. Mixes composition

\begin{tabular}{cccccc}
\hline Mix ID & $\begin{array}{c}\text { Water } \\
\left(\mathrm{L} / \mathrm{m}^{3}\right)\end{array}$ & $\begin{array}{c}\text { Cement } \\
\left(\mathrm{kg} / \mathrm{m}^{3}\right)\end{array}$ & $\begin{array}{c}\text { Fine aggregate } \\
\left(\mathrm{kg} / \mathrm{m}^{3}\right)\end{array}$ & $\begin{array}{c}\text { Coarse aggregate } \\
\left(\mathrm{kg} / \mathrm{m}^{3}\right)\end{array}$ & $\begin{array}{c}\text { Recycled coarse } \\
\text { aggregate }\left(\mathrm{kg} / \mathrm{m}^{3}\right)\end{array}$ \\
\hline Mix A & 160 & 400 & 154.76 & 703.84 & 210.94 \\
Mix B & 160 & 400 & 154.76 & 492.9 \\
\hline
\end{tabular}

\subsection{Sample preparation}

The compressive strength cube test was conducted under both wet and dry curing conditions at 11, 28, 42 and 90 days. At each age and curing condition, six concrete specimens were cast and tested. So, the results of cube testing were the average of $615 \mathrm{~cm}$ cubic specimens, and the total number of cubes was 96 . Before testing in the compression testing machine, two sides of each cubic specimen were tested with the Schmidt rebound hammer and the result of each test was the average of 12 rebound numbers. Therefore, the total number of rebound numbers was 192 under both wet and dry curing conditions at 11, 28, 42 and 90 days. In this study, a manual Type $\mathrm{N}$ hammer was used and the test procedure was based on the recommendations given by ASTM C805 [42]. To securely clamp the cube specimens to the compression testing machine and perform the Schmidt rebound hammer test, a minor load was applied to the cube specimens from two sides using clamp jaws. 
On the other hand, four concrete slabs were cast and cured under each curing condition to drill core specimens at 11 and 28 days, where 2" and 4" core diameters with L/D ratios of 1 and 2 were considered. At each age and curing condition, seven cylindrical specimens were drilled and tested. So, each result of core testing was the average of 7 cylindrical specimens, and the total number of drilled cores was 224 . It is noteworthy that both slabs and cubes were compacted using concrete vibrating table to achieve a similar compaction. This vibrating method was helpful as well to prevent the generation of difference between concrete properties at low and high depths of slabs. Since the strength of the core specimens can be affected by the location of the drilling and the results of drilled cores in the corner zone can be lower than those in the central zone of a slab, a minimum distance of $150 \mathrm{~mm}$ was considered between the hollow core and the slab edges to reduce the effect of location of the drilling on the strength of core specimens.

\section{Results and discussion}

\subsection{Slump}

In this study, the slump of concrete control mix (Mix A) and RAC (Mix B) was equal to 78 $\mathrm{mm}$ and $69 \mathrm{~mm}$, respectively. The slump of RAC in this study was nearly within the range of the results given by Ferreira et al. [43], where the slump of concrete with different substitution levels of recycled aggregate was $80 \pm 10 \mathrm{~mm}$. In addition, the slump value of $60 \mathrm{~mm}$ was obtained by Adnan et al. [44] for concrete with the water-binder ratio of 0.4 and $75 \%$ incorporation of coarse 
recycled aggregate. In this study, the results showed that the slump of control mix (Mix A) was about $13 \%$ higher than that of RAC (Mix B). This could be due to the fact that the coarse recycled aggregate, obtained from crushed concrete, was more angular and rough-textured compared to coarse natural aggregate, although there was no significant difference between the slump values of Mixes A and B, because both recycled and natural aggregates were used in the saturated surface-dry condition to prevent further water absorption. So, the amount of free water in Mix B was nearly the same in Mix A as expected.

\subsection{Cube compressive strength}

Fig. 3 shows the cube compressive strength of the control mix (Mix A) and RAC (Mix B) with $70 \%$ incorporation of coarse recycled aggregate under wet and dry curing conditions at $11,28,28$, 42 and 90 days. According to the experimental results, the cube compressive strength of the control mix and RAC under wet curing conditions was in the range of 24.7-40.2 MPa and 14.8-27.9 MPa, respectively. The corresponding values of the control mix and RAC under dry curing conditions were in the range of 18.2-29.7 MPa and 11-20.6 MPa, respectively. In the study of Wang et al. [45], the 28-day cube compressive strength of RAC with $75 \%$ incorporation of coarse recycled aggregate was $26 \mathrm{MPa}$ under wet curing conditions. This value in the present study, 23.6 MPa, had less than $10 \%$ difference. In addition, the compressive strength of concrete under wet curing conditions was on average about $35 \%$ higher than that under dry curing conditions. So, as 
expected, the curing regimes affect the compressive strength of concrete specimens [46-51] and the difference between wet and dry curing conditions can go up to 50\% as reported by Mamola and Zaniewski [52]. Under wet curing conditions, the cube compressive strength of the control concrete was on average about $47.6 \%$ greater than that of RAC. Nearly the same difference was observed under dry curing conditions. The increase in cube compressive strength, particularly for RAC specimens, was higher at early ages than that at older ages. Regarding this, as revealed by Belin et al. [53] and Zhang et al. [12], the surface of recycled aggregate is more porous compared to that of coarse natural aggregate, and the former can somewhat absorb more water in concrete, leading to a decrease of the hydration process. Therefore, the poor interlock between recycled aggregates and cement paste is inevitable, particularly at older ages.

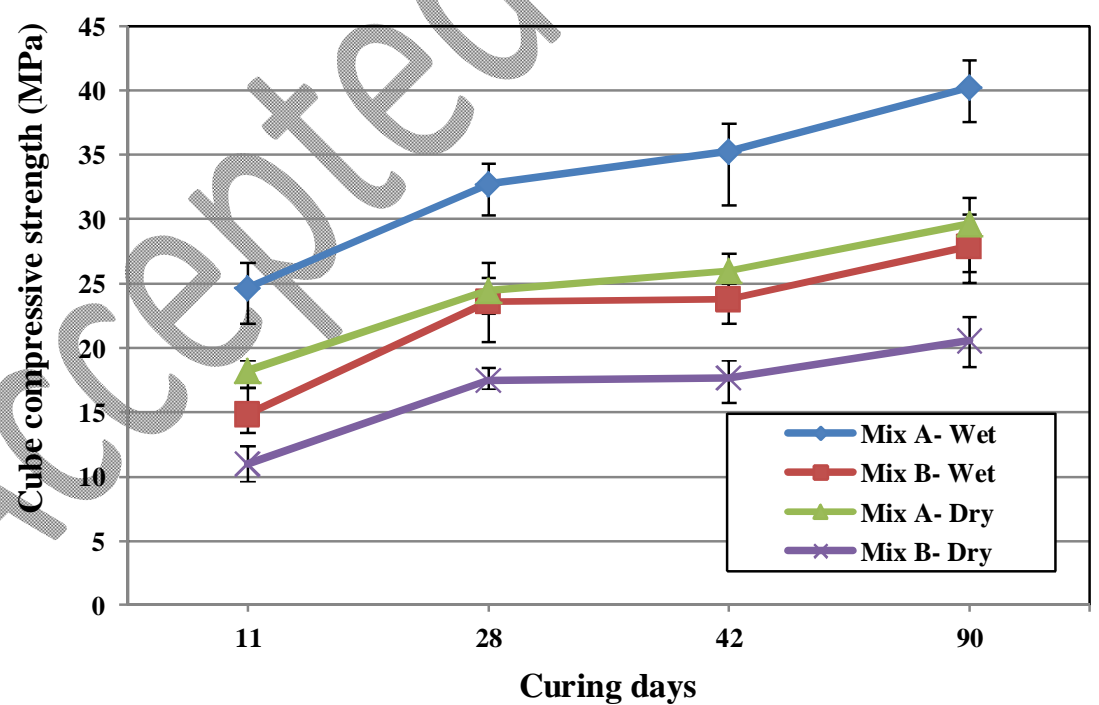

Fig. 3. Cube compressive strength of the control mix (Mix A) and RAC (Mix B) under wet and dry curing conditions 
The mid-values of standard deviation (SD) of the control mix and RAC under wet curing conditions were 2.1 MPa and 1.45 MPa, respectively. The corresponding mid-values under dry curing conditions were 2.5 MPa and 1.9 MPa, respectively. So, there was no significant difference between the SD values under wet and dry curing conditions.

\subsection{Core testing}

Fig. 4 shows the core strength of the control mix (Mix A) and RAC (Mix B) under wet and dry curing conditions at 11 and 28 days. For different L/D ratios, the compressive strength of the control core specimens (Mix A) with a diameter of $2^{\prime \prime}$ was $39 \%$ to $49 \%$ higher than that of the RAC specimens (Mix B) at different ages, These values were between $42 \%$ and $50 \%$ for the core diameter of 4". The core strength of both the control and RAC specimens increased $32-45 \%$ from 11 days to 28 days.

To compare the results of core testing with those compressive strength cube test, Khoury et al. [54] measured the 28-day compressive strength of conventional concrete. They showed that a stress concentration around the core specimens was generated during the coring operation, which was associated with damage in the drilled cylindrical specimens and a subsequent decrease in the strength of cores up to $20 \%$ for diameters less than $100 \mathrm{~mm}$ (4"), compared to the compressive strength cube tests. This may be the reason why the strength of the control and RAC specimens were lower than those of the cubic specimens up to $19 \%$ in the present study. 
As mentioned above, the compressive strength results for an L/D ratio below 1.75 need to be corrected using factors, proposed by ASTM-C42-77 [25] and BS 1881 [26]. As shown in Table 1, the correction factors for L/D ratios of 1 and 2 are 0.8 and 0.87 respectively. In this study, the ratios of core strength between $\mathrm{L} / \mathrm{D}=2$ and $\mathrm{L} / \mathrm{D}=1$ can be obtained using the results of Fig. 4 . These ratios were between 0.83 and 0.87 , within the range of the correction factors proposed by ASTM-C $42-77$ [25] and BS 1881 [26]. Madandoust and Alizadeh [28] revealed that, for wet curing conditions, core strengths for a diameter of $4 "$ were $10 \%$ to $11 \%$ higher than those for a diameter of $2 "$. This range was 9-12\% in the present study, which is in agreement with Madandoust and Alizadeh [28].

As seen in Fig. 4, there was no significant difference between the SD values under wet and dry curing conditions, similarly to the standard cube test. The mid-values of SD for 2" and 4" core diameters with an L/D ratio of 1 were $1.3 \mathrm{MPa}$ and $1.2 \mathrm{MPa}$, respectively. The mid-values for an L/D ratio of 2 were 1.2 MPa and 1.1 MPa, respectively. According to the results, the midvalues of SD for a 2 " core diameter were $9-18 \%$ lower than those for 4 " core diameter. This shows that the SD values can be affected by the size of the specimens, as reported by Madandoust et al. [16], and they have a higher scatter for lower core diameters. 


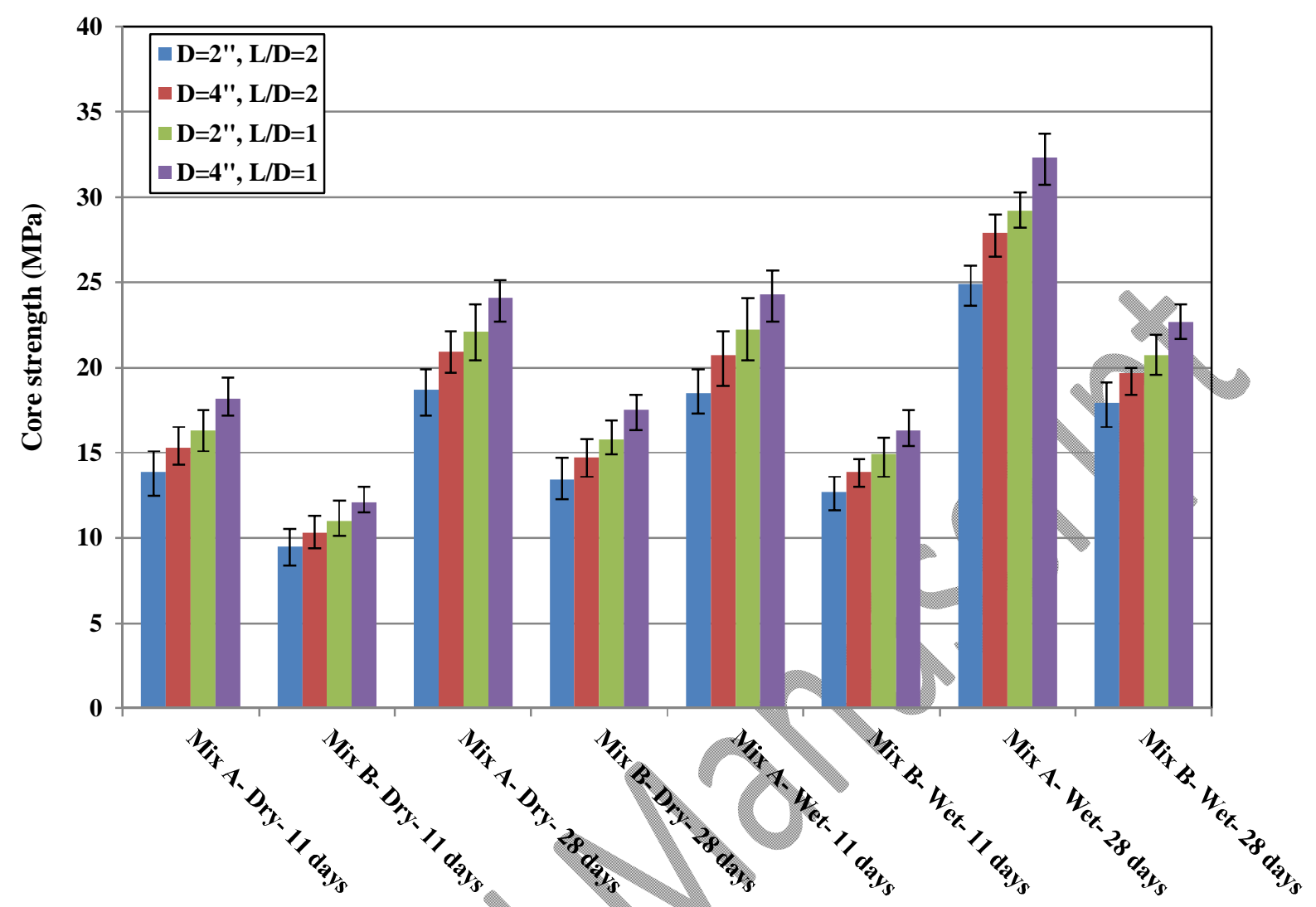

Fig. 4. Core strength of the control mix (Mix A) and RAC (Mix B) under wet and dry curing conditions

\subsubsection{Estimation of in-situ cube strength using core testing results}

Eq. 1 has been proposed by BS1881 [26] for drilled vertically cores, to calculate the estimated in-situ cube strength using core testing results, specifically for plain concrete.

$f_{c}=\frac{3}{1.5+\frac{1}{\frac{L}{D}}} f_{\frac{L}{D}}$

Where $f_{c}$ is the estimated in-situ cube compressive strength and $f_{\frac{L}{D}}$ the measured core compressive strength for different L/D ratios. The estimated in-situ cube compressive strength 
using Eq. 1 and cube compressive strength obtained in this study were compared under wet curing conditions as seen in Table 4.

Table 4. Comparison between the cube compressive strength and the estimated cube compressive strength



For both the control and RAC specimens, the cube compressive strength was between $16 \%$ and $22 \%$ higher than the estimated in-situ cube compressive strengths, obtained using Eq. 1. This difference can be explained by the results of Khoury et al. [54], where they reported that the values of cube compressive strength estimated by various standards are different. These differences can be due to the fact that not all correction factors of the results of core testing are considered by the standards. These factors include the particle size distribution, curing conditions, dimensions of core specimens, direction of drilling, and damages generated by the coring bit. By considering this, although Eq. 1 considered the direction of drilling and L/D ratio, there are other significant factors ignored by BS1881 [26]. This seems to be the reason why there was a difference between the cube compressive strength and estimated in-situ cube compressive strength in our study. 


\subsection{Schmidt rebound hammer test}

The results obtained in the Schmidt rebound hammer test for the control mix (Mix A) and RAC

(Mix B) under wet and dry curing conditions at 11, 28, 42 and 90 days are presented in Table 5.

Table 5. Average values of the rebound number and of its standard deviation

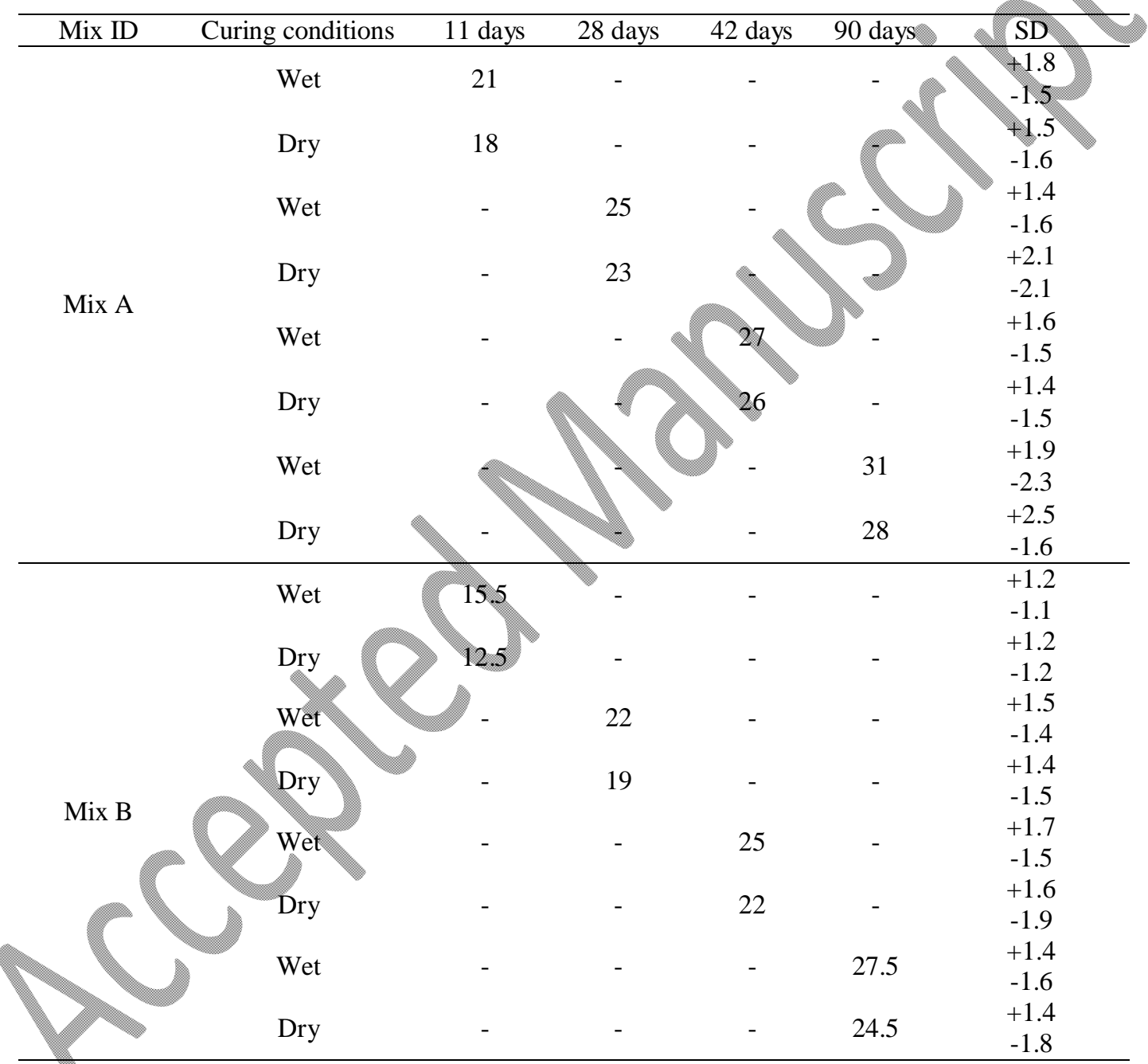

The general trends of the rebound number under both wet and dry curing conditions were similar to those observed in the cube compressive strength. As seen in Table 5, the rebound number of the control mix and RAC under wet curing conditions was in the ranges 18-28 and 15.5-27.5, 
respectively. The corresponding values of the control mix and RAC under dry curing conditions were in the ranges 21-31 and 12.5-24.5, respectively. As expected, the rebound number of RAC was lower than that of the control concrete, due to the porous interfacial zone in the concrete specimens generated by the presence of recycled aggregate, based on a study at the microscopic scale by Poon et al. [55]. This led to poor interlock between recycled aggregate and cement paste and lower compressive strength in the RAC specimens relative to the control concrete specimens.

The mid-values of SD for the control mix and RAC under wet curing conditions were 1.8 and 1.4, respectively. The mid-values under dry curing conditions were 1.8 and 1.5 , respectively. Similarly to what $\mathrm{Xu}$ and $\mathrm{Li}[24]$ observed, the mid-values of SD for the control mix and RAC showed that the rebound number at different locations of cubic concrete specimens were close.

\subsubsection{Comparison of calibration curves}

In Fig. 5, the calibration curves of this study were compared with those of Kaushal [56] for conventional concrete under both wet and dry curing conditions. Two exponential equations (singlevariable equations) of $f_{c}=10.39 e^{0.04 r}$ and $f_{c}=7.977 e^{0.05 r}$ with high correlation coefficients $\left(R^{2}\right)$ of 0.92 and 0.97 forwet and dry curing conditions, respectively, were obtained for the control mix (Mix A), where $\mathrm{r}$ is the rebound number and $f_{c}$ is the estimated compressive strength. The results showed that the estimated compressive strengths of conventional concrete using these two equations were close to the compressive strength obtained by Kaushal [56] and that the trends were similar. 
The calibration curves of the control concrete and RAC were compared under both wet and dry curing conditions, as seen in Fig. 5. Two exponential equations (single-variable equations) of $f_{c}=6.813 e^{0.05 r}$ and $f_{c}=5.958 e^{0.05 r}$ with high correlation coefficients $\left(R^{2}\right)$ of 0.941 and 0.94 for wet and dry curing conditions, respectively, were obtained for RAC (Mix B). Generally, all equations for the control concrete and RAC can reliably predict the compressive strength.



Fig. 5. Comparison between the calibration curves of the Schmidt rebound hammer test

\subsubsection{Schmidt hammer compressive strength}

As shown in Fig. 6, the values of Schmidt hammer compressive strength were obtained for the control concrete and RAC using the equations proposed in Fig. 5.

Under wet curing conditions, the Schmidt hammer compressive strength of control concrete was on average about $44.9 \%$ higher than that of RAC. This value under dry curing conditions was found 
to be $46.1 \%$. Similarly to what was observed in the cube compressive strength, the Schmidt hammer compressive strength of RAC under both wet and dry curing conditions remarkably increased at early ages, while a moderate increase occurred in most cases at older ages. For instance, the compressive strength of RAC under wet curing conditions increased up to $39.1 \%$ from 11 to 28 days. This increase was equal to $16.7 \%$ from 28 to 42 days and thereafter, a $12.2 \%$ enhancement was obtained from 42 to 90 days. According to microscopic studies by Tam and Tam [57] and Li et al. [58] on recycled aggregate, recycled aggregate absorbs water from the mix and over time this trapped water can lead to bleeding of concrete. Then, after water evaporation, more porous transition zone is generated in the RAC specimen. Therefore, the quality of the bond between recycled aggregate and cement paste decreases, leading to the lower Schmidt hammer compressive strength of RAC. Another aspect is that the recycled aggregate was used in the saturated surface-dry condition in this study to prevent further water absorption. Therefore, at early ages, the trapped water molecules in the recycled aggregate were given back to the empty capillary pores to increase the amount of free water in the concrete mixes, leading to an increase in the rate of the hydration process. This process led to a remarkable increase in compressive strength of concrete at early ages. Over time, the free water in concrete mixes evaporated and the remaining water decreased in concrete mixes. So, there was no sufficient water to react with the cement particles and complete the hydration process. That is why a moderate increase occurred in most cases at older ages. 


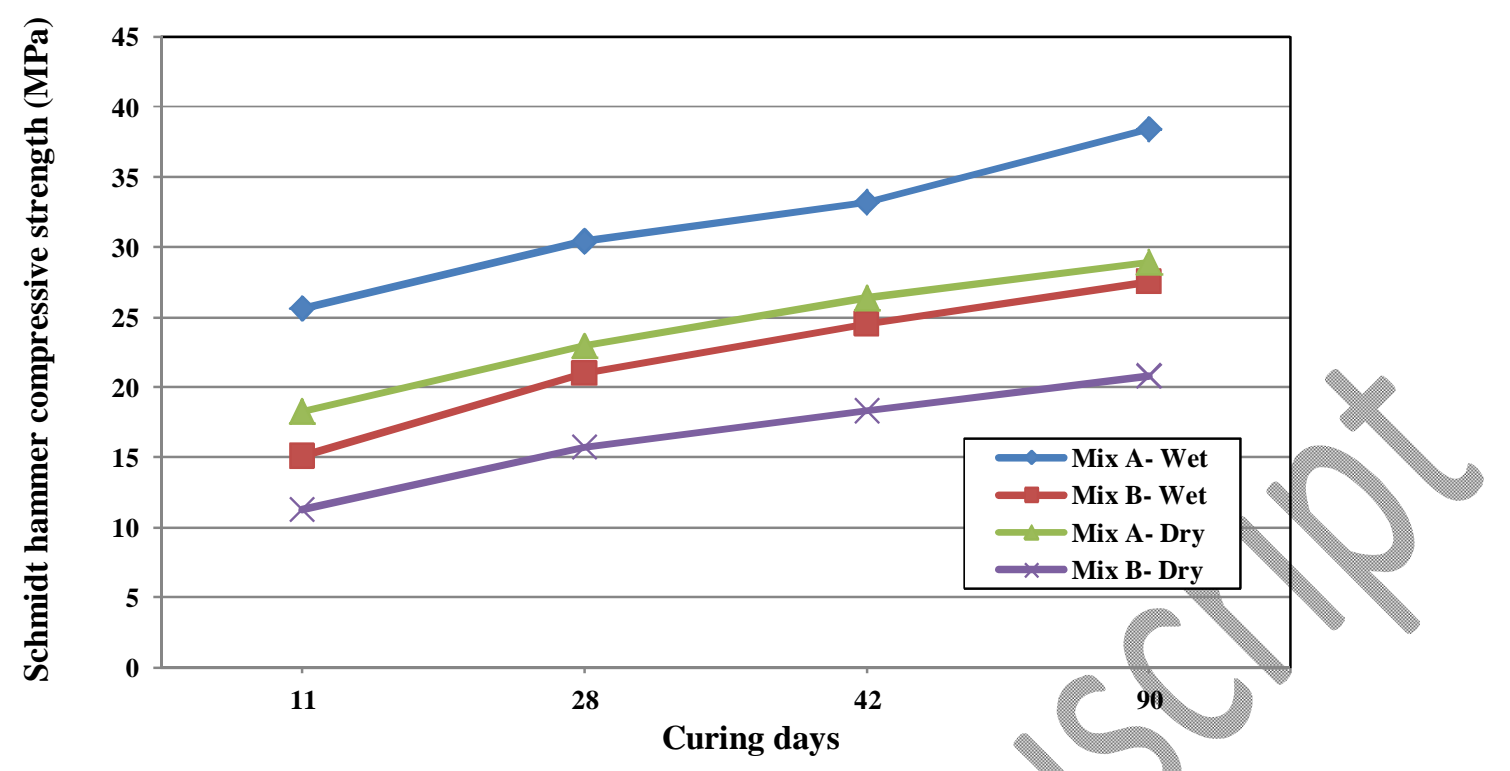

Fig. 6. Schmidt hammer compressive strength

\subsection{Two-variable equation between Schmidt rebound hammer and core testing}

The results of the control concrete and RAC, obtained by the Schmidt rebound hammer, core and cube testing, were used under both wet and dry curing conditions 11 and 28 days to determine a reliable two-variable equation to estimate the compressive strength of concrete specimens. In Table 6, the results of specimens No. 4 to 8 were randomly selected and used to obtain the two-variable equation (Eq. 2) with high correlation coefficient $\left(R^{2}\right)$ of 0.99 .

$\mathrm{f}_{\mathrm{c}}=1.073 \mathrm{C}+0.229 \mathrm{R}-2.755$

Where $\mathrm{f}_{c}$ is the estimated compressive strength, $\mathrm{C}$ is the drilled core compressive strength with $\mathrm{L} / \mathrm{D}$ ratio of 2 , and $\mathrm{R}$ is the rebound number. Then, results No. 1 to 3 in Table 6 were employed to test the reliability of Eq. 2. It is noteworthy that the drilled core compressive 
strengths in Table 6 were for the L/D ratio of 2 . Table 7 compares the results of the standard cube test with those of the Schmidt hammer, core testing, and the two-variable equation, where the differences between them are expressed as percentages in parentheses. The differences between the standard cube test and the Schmidt hammer test results were $10 \%$ at the most and increased to $15.5 \%$ between the standard cube test and the core testing results, while there was less than $5.4 \%$ difference between the results of the standard cube test and those of the twovariable equation. Therefore, it seems that the estimated compressive strength by two-variable equation is more reliable than that of either the Schmidt hammer or the core testing.

Table 6. Results used to obtain and test the two-variable equation

\begin{tabular}{cccc}
\hline No. & Cube compressive strength (MPa) & Drilled core compressive strength (MPa) & Rebound number \\
\hline 1 & 17.4 & 14.7 & 19 \\
2 & 14.8 & 13.9 & 15.5 \\
3 & 32.7 & 27.9 & 25 \\
4 & 18.2 & 15.3 & 18 \\
5 & 10.9 & 10.3 & 2.5 \\
6 & 24.4 & 20.9 & 21 \\
7 & 24.4 & 20.7 & 22 \\
8 & 23.6 & 19.7 & 2 \\
\hline
\end{tabular}

As mentioned previously, the cube compressive strength was between $16 \%$ and $22 \%$ above the estimated in-situ cube compressive strength using Eq. 1, proposed by BS1881 [26]. On the other hand, although some reliable exponential equations were obtained using the Schmidt rebound hammer test to estimate the compressive strength as seen in Fig. 5, these equations were different for the control concrete and RAC and for the two curing conditions. So, considering the fact that the differences between the estimated compressive strength estimated by the twovariable equation and the cube compressive strength were less than $5.4 \%$, as seen in Table 7 , it 
can be inferred that the this equation can reliably predict the compressive strength of conventional concrete and RAC under both wet and dry curing conditions, and it seems to be more promising than the exponential equations of the Schmidt rebound hammer test.

Table 7. Comparisons between measured and estimated in-situ cube strength

\begin{tabular}{ccccc}
\hline No. & Measured cube strength (MPa) & \multicolumn{3}{c}{ Estimated cube strength } \\
\cline { 2 - 5 } 1 & & By Schmidt hammer (MPa) & By core test (MPa) & By the two-variable equation (MPa) \\
2 & 17.4 & $15.7(10 \%)$ & $14.7(15.5 \%)$ & $16.6(4.6 \%)$ \\
3 & 14.8 & $15.1(2 \%)$ & $13.9(6 \%)$ & $15.6(5.4 \%)$ \\
\hline & 32.7 & $30.4(7 \%)$ & $27.9(14.7 \%)$ & $34.1(4.3 \%)$ \\
\hline
\end{tabular}

\section{Conclusion}

In this study, the Schmidt rebound hammer, core and cube testing were used to assess the compressive strength of RAC under wet and curing conditions at different ages. The following conclusions can be drawn from the experimental investigation:

- The cube compressive strength of concrete specimens under wet curing conditions was on average about $35 \%$ higher than that under dry curing conditions. In addition, the strength of the control concrete specimens was on average about $47 \%$ higher than that of the RAC specimens under both wet and dry curing conditions;

The core strength of the control concrete and RAC specimens was up to $19 \%$ less than

that of the cubic specimens. Moreover, the 4" diameter strength was between $9-12 \%$ higher than that of the 2" diameter core;

- The range of the correction factors for drilled core specimens of the control concrete and RAC was between 0.83 and 0.87 , which were within the values proposed by ASTM-C42- 
77 and BS 1881. For both the control concrete and RAC specimens, the results showed that the cube compressive strength was $16-22 \%$ higher than the in-situ cube compressive strength estimated using the equation proposed by BS1881;

- The Schmidt hammer compressive strength of the control concrete was on average about $44.9 \%$ and $46.1 \%$ higher than that of RAC under wet and dry curing conditions, respectively;

- Based on the results of the Schmidt rebound hammer, core and cube testing, the compressive strength of RAC under both wet and dry curing conditions remarkably increased at early ages, while a moderate increase occurred in most cases at older ages;

- In core testing, there was no significant difference between the SD values under wet and dry curing conditions, similarly to the standard cube test. In addition, the mid-values of SD for 2" diameter core were 9-18\% less than those for 4" diameter core. In the Schmidt rebound hammer test, the rebound number at different locations of cubic specimens was close;

- According to the data calibrations, for specific situations similar to what was considered in this study, the differences between the standard cube test and the Schmidt hammer test results increased to $10 \%$, while there was less than $5.4 \%$ difference between the results of the standard cube test and those of the two-variable equation. Therefore, the two-variable equation between Schmidt rebound hammer and core testing reliably estimated the compressive strength of conventional concrete and RAC under both wet and dry curing conditions at different ages, and it was more promising than the exponential equations of 
the Schmidt rebound hammer test.

\section{References}

1. H. Taherkhani, Evaluation of the physical properties of unbound base layer containing recycled aggregates, International Journal of Environmental Science and Development, 6 (4) (2015) 279-285.

2. M. Saberian, J. Li, B.T. Nguyen, S. Setunge, Estimating the resilient modulus of crushed recycled pavement materials containing crumb rubber using Clegg impact value, Resources, Conservation and Recycling, 141 (2019) 301-307.

3. S. Frondistou-Yannas, Economics of concrete recycling in the United States, Adhesion Problems in the Recycling of Concrete, 4 (1981) 163-185.

4. S.B. Huda, M.S. Alam, Mechanical behavior of three generations of $100 \%$ repeated recycled coarse aggregate, concrete, Construction and Building Materials, $65(4)(2014) 574-582$.

5. M. Saberian, J. Li, B.T. Nguyen, G. Wang, Permanent deformation behaviour of pavement base and subbase containing recycle concrete aggregate, coarse and fine crumb rubber, Construction and Building Materials, 178 (2018a) 51-58.

6. J. Li, M. Saberian, B.T. Nguyen, Effect of crumb rubber on the mechanical properties of crushed recycled pavement materials. Journal of Environmental Management, 218 (2018) 291-299.

7. Y. Zaetang, V. Sata. A. Wonsan, P. Chindaprasirt, Properties of pervious concrete containing recycled concrete block aggregate and recycled concrete aggregate, Construction and Building Materials, 111 (2016) 15-21.

8. J. Pacheco, J. de Brito, C. Chastre, L. Evangelista, Experimental investigation on the variability of the main mechanical properties of concrete produced with coarse recycled concrete aggregates, Construction and Building Materials, 201 (2019) 110-120.

9. J.N. Pacheco, J. de Brito, C. Chastre, L. Evangelista, Probabilistic conversion of the compressive strength of 
cubes to cylinders of natural and recycled aggregate concrete specimens, Materials,12(2) (2019) 280.

10. S. Frondistou-Yannas, Waste concrete as aggregate for new concrete, ACI Materials Journal, 74(8) (1977) $373-376$.

11. A. Ajdukiewicz, A. Kliszczewicz, Influence of recycled aggregates on mechanical properties of HS/HPC, Cement and Concrete Composites, 24(2) (2000) 269-279.

12. J. Zhang, C. Shi, Y. Li, X. Pan, C.-S. Poon, Z. Xie, Influence of carbonated recycled concrete aggregate on properties of cement mortar, Construction and Building Materials, 98 (2015) 1-7.

13. P. Zhu, X. Zhang, J. Wu, X. Wang, Performance degradation of the repeated recycled aggregate concrete with $70 \%$ replacement of three-generation recycled coarse aggtegate, Jounnal of Wuhan University of Technology-Materials Science Edition, 31(5) (2016) 989-995.

14. V.W.Y. Tam, C.M. Tam, Y, Wang, Optimization on proportion for recycled aggregate in concrete using twostage mixing approach, Construction and Building Materials, 21(10) (2007) 1928-1939.

15. R. Madandoust, M. Kazemi, Numerical analysis of break-off test method on concrete, Construction and Building Materials, 151 (2017) 487-493.

16. R. Madandoust, Z.F.Z. Bazkiyaei, M. Kazemi, Factor influencing point load tests on concrete, Asian Journal of Civil Engineering, 19(8) (2018) 937-947.

17. D. Soares, J. de Brito, J. Ferreira, and J. Pacheco, In situ materials characterization of full-scale recycled aggregates concrete structures, Construction and Building Materials, 71 (2014) 237-245.

18. J.H. Bungey, S.G. Millard, M.G. Grantham, Testing of concrete in structures ( $4^{\text {th }}$ ed., p. 352). London: Taylor \& Francis. (2006).

19. ACI 228.1R-03, In-place methods to estimate concrete strength, Report by ACI Committee 228, American Concrete Institute, September, (2003).

20. J. Kolek, An appreciation of the Schmidt rebound hammer, Magazine of Concrete Research, 10(28) (1958) 
27-36.

21. D.J. Victor, Evaluation of hardened field concrete with rebound hammer, ACI Materials Journal, 37(11) (1963) 407-411.

22. G.W. Greene, Test hammer provides new method of evaluating hardened concrete, ACI J. Proc. 51(11) (1954) 249-256.

23. W.E. Grieb, Use of Swiss hammer for establishing the compressive strength of hardened concrete, Public Roads, (201) (1958) 1-14.

24. T. Xu, J. Li, Assessing the spatial variability of the concrete by the rebound hammer test and compression test of drilled cores, Construction and Building Materials, 188 (2018) 820-832.

25. ASTM-C42-77, Standard method of obtaining and testing drilled cores and sawed beams of concrete. American Society for Testing and Materials, West Conshohocken, Pa, USA, 1978.

26. BS-1881-120, Testing concrete method for determination of the compressive strength of concrete cores, British Standards Institute, London, UK, 1983.

27. S. Sharma, P.K. Aggarwal, S: Naval, Experimental study of core diameter varying H/D on concrete, International journal of Engineering Research \& Technology, 2(3) (2013).

28. R. Madandoust, A.M. Almadeh, Assessing the effective parameters on normal strength concrete by core testing. Joumal of Automotive and Applied Mechanics, 3(2) (2015) 17-21.

29. R.D. Gaynor, Effect of horizontal reinforcing steel on the strength of molded cylinders, ACI Materials Joưrnal, 62(7) (1965) 837-840.

30. Y.H. Loo, C.W. Tan, C.T. Tam, Effects of embedded reinforcement on measured strength of concrete cylinders. Magazine of Concrete Research, 41(164) (1989) 11-18.

31. F. Debieb, S. Kenai, The use of coarse and fine crushed bricks as aggregate in concrete. Construction and Building Materials, 22(5) (2008) 886-893. 
32. R. Latif Al-Mufti, A.N. Fried, The early age non-destructive testing of concrete made with recycled concrete aggregate, Construction and Building Materials, 37 (2012) 379- 386.

33. B.B. Mukharjee, S.V. Barai, Influence of nano-silica on the properties of recycled aggregate concrete. Construction and Building Materials, 55 (2014) 29-37.

34. S. Jahandari, M. Saberian, Z. Tao, S. Faridfazel Mojtahedi, J. Li, M. Ghasemi, S.S. Rezvani, W. Li, Effects of saturation degrees, freezing thawing, and curing on geotechnical properties of lime and lime-cement concretes, Cold Regions Science and Technology. 160 (2019) 242-251.

35. H. AzariJafari, A. Kazemian, M. Rahimi, A. Yahia, Effects of pre-soaked super absobent polymers on fresh and hardened properties of self-consolidating lightweight concrete, Construction and Building Materials, 113 (2016) 215-220.

36. H. AzariJafari, M.J.T. Amiri, A. Ashrafian, H. Rasekh, M.J. Barforooshi, J. Berenjian, Ternary blended cement: an eco-friendly alternative to improve resistivity of high-performance self-consolidating concrete against elevated temperature, Journal of Cleaner Production, 223 (2019) 575-586.

37. S. Jahandari, M. Saberian, F. Zivari, J. Li, M. Ghasemi, R. Vali, Experimental study of the effects of curing time on geotechnical properties of stabilized clay with lime and geogrid, International Journal of Geotechnical Engineering, 13:2) (2019) 1-12.

38. M.M. Khotbehsara, B.M. Miyandehi, F. Naseri, T. Ozbakkaloglu, F. Jafari, E. Mohseni, Effect of $\mathrm{SnO}_{2}$, $\mathrm{ZrO}_{2}$, and $\mathrm{CaCO}_{3}$ nanoparticles on water transport and durability properties of self-compacting mortar containing fly ash: Experimental observations and ANFIS predictions, Construction and Building Materials, 158 (2018) 823-834.

39. H. AzariJafari, M. Shekarchi, J. Berenjian, B. Ahmadi, Enhancing workability retention of concrete containing natural zeolite by superplasticizers' combination. Special Publication, 302 (2015) 416-424.

40. E. Mohseni, F. Naseri, R. Amjadi, M.M. Khotbehsara, M.M. Ranjbar, Microstructure and durability 
properties of cement mortars containing nano- $\mathrm{TiO}_{2}$ and rice husk ash, Construction and Building Materials, 114 (2016) 656-664.

41. M.M. Khotbehsara, E. Mohseni, M.A. Yazdi, P. Sarker, M.M. Ranjbar, Effect of nano-CuO and fly ash on the properties of self-compacting mortar, Construction and Building Materials, 94 (2015) 758-766.

42. ASTM C805, Standard test method for rebound number of hardened concrete. West Conshohocken, Pa, USA, 2002.

43. L. Ferreira, J. de Brito, and M. Barra, Influence of the pre-saturation of recycled coarse concrete aggregates on the fresh and hardened properties of concrete, Magazine of Concrete Research, 63 (8) (2011) 617-627.

44. S.H. Adnan, Y.L. Lee, I.A. Rahman, H.M. Saman, and M.V. Soejoso, Compressive strength of recycled aggregate to concrete with various percentage of recycled aggregate, Proceedings of National Seminar on Civil Engineering Research, SEPKA, Johor Bahru, Malaysia, (2007).

45. P. Wang, X.G. Zhang, F. Wang, M.R. Deng, W.B. Qin, Q. Tian, Test study on cube compressive strength of recycled lightweight aggregate concrete, $2^{\text {nd }}$ Annual International Conference on Advanced Material Engineering, (2016).

46. M. Saberian, S. Jahandari, J. Li, F. Zivari, Effect of curing, capillary action, and groundwater level increment on geotechnical properties of lime concrete: Experimental and prediction studies, Journal of Rock Mechanics and Geotechnical Engineering, 9(4) (2017) 638-647.

47. S. Jahandari, M.M. Toufigh, J. Li, M. Saberian, Laboratory study of the effect of degrees of saturation on lime concrete resistance due to the groundwater level increment, Geotechnical and Geological Engineering, 36(1) (2018) 413-424.

48. M. Koushkbaghi, P. Alipour, B. Tahmouresi, E. Mohseni, A. Saradar, P.K. Sarker, Influence of different monomer ratios and recycled concrete aggregate on mechanical properties and durability of geopolymer concretes, Construction and Building Materials, 205 (2019) 519-528. 
49. A. Sadrmomtazi, S. Tajasosi, B. Tahmouresi, Effect of materials proportion on rheology and mechanical strength and microstructure of ultra-high performance concrete (UHPC), Construction and Building Materials, 187 (2018) 1103-1112.

50. M. Hajforoush, R. Madandoust, M. Kazemi, Effects of simultaneous utilization of natural zeolite and magnetic water on engineering properties of self-compacting concrete, Asian Journal of Civil Engineering, 20(2) (2019) 289-300.

51. Jahandari, S. (2015) Laboratory study of moisture and capillarity impact on lime concrete resistance due to the increase of ground water level. M.Sc. thesis, Faculty of Civil and Surveying Engineering, Department of Geotechnical Engineering, Graduate University of Advanced Technology, Kerman, Iran.

52. M.S. Mamlouk, J.P. Zaniewski, Materials for civil and construction engineers. $2^{\text {nd }}$ ed., New Jersey: Pearson Prentice Hall, (2006).

53. P. Belin, G. Habert, M. Thiery, M. Thiery, Cement paste content and water absorption of recycled concrete coarse aggregates, Materials and Struetures, 47(9) (2014) 1451-1465.

54. Sh. Khoury, A.A.H. Aliabdo, A. Chazy, Reliability of core test - Critical assessment and proposed new approach, Alexandria Engineering Journal, 53(1) (2014) 169-184.

55. C.S. Poon, Z.H. Shui, L. Lam, Effect of microstructural ITZ on compressive strength of concrete prepared with recycled aggregates, Construction and Building Materials, 18(6) (2004) 461-468.

56. K. Kaushal, Testing hardened concrete by surface hardness. Indian Concrete Institute, Bulletin No. 20 (1987) $17-20$.

57. V.W.Y. Tam, C.M. Tam, Diversifying two-stage mixing approach (TSMA) for recycled aggregate concrete: TSMAs and TSMAsc, Construction and Building Materials, 22(10) (2008) 2068-2077.

58. J. Li, H. Xiao, Y. Zhou, Influence of coating recycled aggregate surface with pozzolanic powder on properties of recycled aggregate concrete, Construction and Building Materials, 23(3) (2009) 1287-1291. 